\title{
Analysis of Child Computer Interaction in Edutainment and Simulation Games Application on Android Platform in Indonesia
}

\author{
Setia Wirawan \\ Faculty of Computer Science and \\ Information Technology \\ Gunadarma University \\ Depok, Indonesia
}

\author{
Faris Fajar Muhammad, Lutfi \\ Dwi Saifudin, Mustafa Ibrahim \\ Faculty of Computer Science and \\ Information Technology \\ Gunadarma University \\ Depok, Indonesia
}

\author{
Dewi Agushinta R. \\ Faculty of Computer Science and \\ Information Technology \\ Gunadarma University \\ Depok, Indonesia
}

\begin{abstract}
Child Computer Interaction (CCI) has become a challenge in utilizing the technology as education media. The increasing number of children, who use advanced gadgets in Indonesia such as smartphones and tablet PCs, provides a new space for developing interactive educational game application for kids. Indonesia is a country with the biggest number of Androidbased game application downloaders in the world of service providers. Modeling serious game that has been chosen to deliver the concept is Edutainment and Simulation Games. This paper will analyze and review the application of the two concepts of the game, using data on the ranking from one of the top application service providers in analytic applications. The game application developers are expected to understand CCI and develop applications concepts that suit the needs of children in Indonesia. This will create market opportunities in the Indonesian game industry in the future.
\end{abstract}

Keywords-Child Computer Interaction; Edutainment; Game application; Simulation Games

\section{INTRODUCTION}

In the recent years, the use of information and communication technologies used by the children is increasing. Especially with the development of advanced gadget with a variety of forms. Ranging from smartphones, to tablet PCs, they dominate the market with a lot of communication tools. Business people in information technology domain have also begun to take special care in the kids market.

This change provides an opportunity for the developers to start developing applications that fit the diverse needs of all players. Both in terms of usability, and in terms of user satisfaction. This has brought about the development application to the generation of more interactive and allows the interaction of children and computers to be studied. This interaction is called the Child Computer Interaction (CCI). The interaction process combines the input and perspectives of. several scientific disciplines that support research and industrial aspects related to interactive systems for children. CCI is defined as" the study of Activities, Behaviours, Concerns and Abilities of Children as they interact with computer technologies, often with the intervention of others (mainly adults) in situations that they partially (but generally do not fully) control and Regulate" [1, 2].
Child Computer Interaction (CCI) is a sub-science of the development of Human Computer Interaction (HCI), with an average age of interest in study of children ranging between the ages of five to twelve years [1]. The discipline of psychology is also emphasized to establish the mindset and behavior of childrens to use the system architecture designed. Contribution of science and language arts also affects how the display allows children to explore the information and instructions to be carried out.

CCI research used many approaches to the art of design, ergonomic characteristics, as well as the interactions that occur. However, many implementations of this approach is not suitable for children. It is based on the different abilities and expectations that each user get [3]. There are many designers created the application design that are not oriented for child user, experience in playing an application. If in the first time a child cannot use the application, the developer is deemed to have failed in developing the application [4].

Basically, there are three main categories that support the development of children. Those are Cognitive Development; Physical Development and Social/ Emotion Development [3]. Cognitive Development related to the processing of information, intellectual, and mental health of a child. Physical Development related to the coordination of movements that occur during the interaction between the child with the system, particularly with the existing interface. While Social/ Emotional Development describes how the socialization and emotional processes engaged by the user in response to the interaction. Whether positive or negative, the influence of these three will determine how the design of the application is made. Although it is not dominant and balanced in its implementation in the application for the child. These three aspects should be contained in it. This is what creates the characteristics of each application used.

One of the most common methods used to approach the $\mathrm{CCI}$ is a game application. Especially revealed that play is very important element for healthy child development [5]. The implementation has been realized by many applications that are developed in android platform. The emergences of many models are applied to make the demand for utilization of instructional media used in the application. Edutainment and 
Simulation games become the main aim for developer as children like to play in. This article analyzes how the children in Indonesia can play both the current concept of the application.

\section{CCI IN GAME APLICATION ON ANDROID PLATFORM}

The development of games application on android platform, cannot be separated from the development of mobile industry since the first era of mobile phone was popularized in the end of the 20th century. At that time, mobile application only consists of a few simple games and applications to support mobility such as calendar, alarm, calculator, etc [6]. Fast development in the mobile industry creates an evolution of the mobile content and mobile application. Until now mobile phone has its own operating system. Platform as a special term has change the standard environment for mobile phone to a more powerful gadget that support human activity. This change also give a drastic impact to the development of game application.

Today, the ease of the touchscreen also gives an influence to the application developer. Design interface, game concept, or either the variant of feature have been added to the application to reach all the user, especially children. In the development, the design assumption of the application which support CCI for the children, only choose an interface that suitable in adults. By adding some animation, and brightful color make automatically suit to the children [7]. But, actually it is not as easy as we just figure out. The demand of using game application media has changed, not only educative, but also has some aspect that children need.

Serious games are considered as interest thing to talk to be developed in learning CCI because it designed to give effect to the user beside the pure aspect, which is entertainment [8]. Study process also has to be covered well. Edutainment and Simulation games are two type of serious game concept which is the most often developed. Both in terms of usability, and in terms of the density of existing knowledge.

\section{A. Edutainment Games}

Conventional education process used to deliver the knowledge. Limited human resources and time have become a constraint to deliver information to children. The new alternative way is needed to do study activity by entertaining and giving happiness without any assistant. Edutainment application becomes the new concept from it paradigm.

Edutainment refers to any kind of education that also entertains even though it is usually associated with video games with educational aims. The primary target group was preschool and young children [9]. Indonesian children from 5 years old until 7 years old become their users target. In general, edutainment represents the basic knowledge which can be used in life in the society with focus on reading, mathematics, and science [9]. Edutainment applications are more support to cognitive development of a child, by using interesting and easy to understand picture. This is because of edutainment only developing low level thinking.

The phenomenon of Edutainment signed by the increase of relation between needed for education and expectation of the quality of entertain given [10]. There are many ways to present Edutainment application. Edutainment representation can be divided from its purpose and its content: for improving user life control (informal education), which usually presented by a discussion or a narration. And the second one is giving user an experience (skills education), which is usually presented with such experience simulation [11]. "Alphabet Find" are one of application who represented edutainment application.

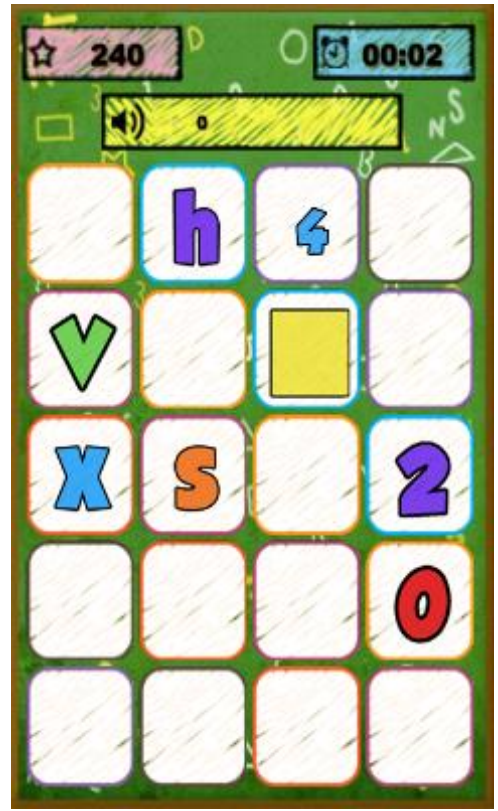

Fig.1. Application "Alphabet Find" [12]

The information learning process to a child in edutainment application will be created as easy as possible and simple as well. So, the children will be able to use the application easily. As we can see in the figure 1, the use of letter and number plus some colorful color effect help children to understand what the information is about. When the child understand what is the purpose of the application they played, then the game will be interesting to play from the point of player view. However, edutainment software will fail since it resulted in what has been described as "boring games and drill-and-kill learning" [13].

\section{B. Simulation games}

If viewed from certain perspective, the reaction for making decision based on condition will be different for each user. User experience and abilities will take a big part in how the user will react when facing the issue. To make studying those issue more effective, simulation model was created. Literally, simulation is popularly defined as a partial representation of reality which selects crucial characteristics of a real situation and makes a replica of them, within an environment or place which is basically free of risk [14].

With the potential exists inside gaming industry, many professionals and tutor attracted to simulation games. Firstly, there is a big change in the field of conventional teaching. It is the development from "learning by hearing" process to 
"learning by doing" [15]. Moreover, Simon (1996) note "how we learn already change from memorizing information to find and use the information player found". An interactive simulation will give children chance to face the issues directly and solve it with their own way. The second reason is some prove from empiric study claimed that game can become a tools to improve learning a complex material [15]. And the last one that makes this concept interesting is simulation game is more effective than the other learning method because at the same time it trains affective and cognitive process [16]. An example for game application based on simulation game is social reality, driving simulation, operation simulation, etc.

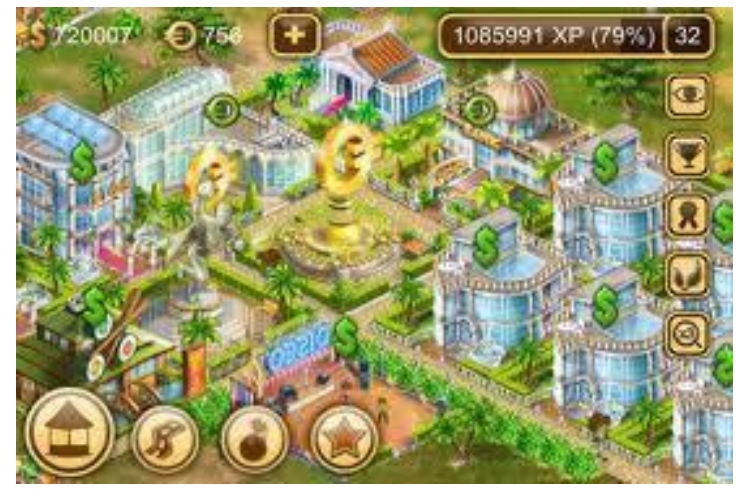

Fig.2. "Paradise Island” application [17]

In the figure 2, game aplication "Paradise Island" described a condition close to reality used for training media. There is an island player can manage and organize their resource. By managing those two things, user can learn how to implement those condition in reality. Player can learn how to think logically.

\section{MODEL ANALYSIS AND ASSUMPTION}

This article uses data from a leading analytic applications. From these data we are sorting it based on initial concepts that will be the first presumption by the children. This is because we see that some kinds of applications is very difficult to find in some literatures. We use the top ranked 50 on a game application that we expect to represent users in Indonesia. The initial concepts used as a starting point to see how the presentation of the concept of Edutainment applications and applications that are presented with the concept of simulation games will be shown on table 1 .

As one form of analysis, presentation of the results of the classification form Edutainment application shown in Fig 3.

Based on the literature edutainment game applications, these applications are based on the design of a lightweight and straight to the main of the desired concept.

\section{TABLE I. LITERATURE CONCEPT}

\begin{tabular}{|l|l|}
\hline \multicolumn{1}{|c|}{$\begin{array}{c}\text { Edutainment Games } \\
\text { Applications Presentation }\end{array}$} & \multicolumn{1}{c|}{$\begin{array}{c}\text { Simulation Games } \\
\text { Application Presentation }\end{array}$} \\
\hline $\begin{array}{l}\text { Implementation in the form of } \\
\text { elementary instruction for } \\
\text { children. }\end{array}$ & $\begin{array}{l}\text { Implementation } \\
\text { in the form of } \\
\text { modelingreal events. }\end{array}$ \\
\hline $\begin{array}{l}\text { Children are required } \\
\text { to follow rules and } \\
\text { instructions. }\end{array}$ & $\begin{array}{l}\text { Children are required } \\
\text { to explore the modeling } \\
\text { that has been provided. }\end{array}$ \\
\hline $\begin{array}{l}\text { Game application presents } \\
\text { a counting process in } \\
\text { mathematics, reading } \\
\text { and science. }\end{array}$ & $\begin{array}{l}\text { Game application presents } \\
\text { thef process of creativity } \\
\text { and problem resolution } \\
\text { in accordance with the } \\
\text { wishes of the player. }\end{array}$ \\
\hline $\begin{array}{l}\text { Children are required } \\
\text { to know directly what the } \\
\text { application presented }\end{array}$ & $\begin{array}{l}\text { Children are required } \\
\text { to see what the problem } \\
\text { represented }\end{array}$ \\
\hline
\end{tabular}
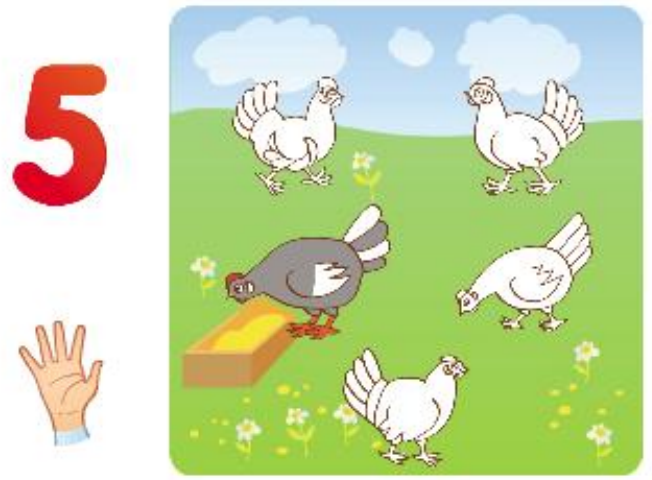

Fig.3. Example of edutainment game application [18]

Introducing numbers with the use of animal images that have been provided for imaging a portrait of five numbers. This application is also intended to stimulate children to use fingers to count. When viewed closely, there is a navigation to continue or return to the other to study the numbers. Based on this, the form of presentation of the application is classified as edutainment applications.

Then, the presentation of simulation games are seen on pieces of game play showed in Figure 4. One ice cream shop modeling simulation was chosen to be used by this application. The children will be invited to see a store with a lot of dessert food.

When kids play this game, then freedom in managing resources will depend on what will the player does. Existing learning theories in this game put emphasis indirectly on the development of a child's creativity in dealing with a case/ matter by solving the problems in the shop. Presumptions about the shop's children are expected to learn how to take care of the store with exploring added to the store. 


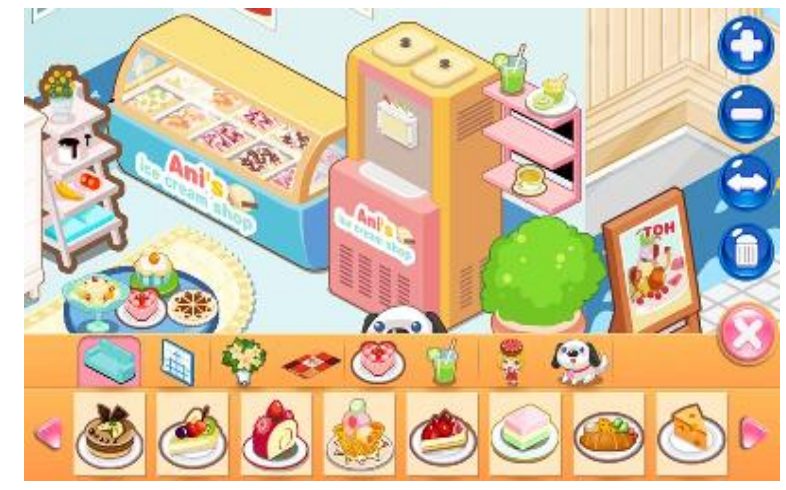

Fig.4. example simulation games application presented [19]

\section{RESULT}

Based on the guidelines presented in Table 1, the results shown in Fig 5.

\section{Games Application represented}

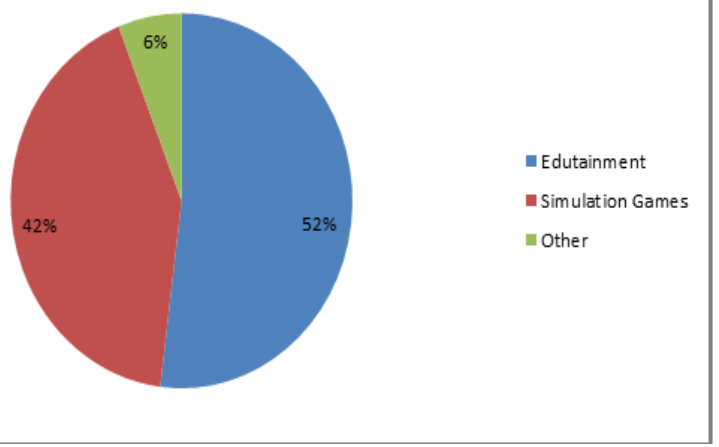

Fig.5. Games Application Represented Diagram [20]

The data who were calculated, got from Distimo Analytics for SamsungApps for free application in Indonesia, may 23 2013. As shown in Fig 5, the presentation of applications nearly balanced. 52\% more game applications are presented in the form of edutainment, while $42 \%$ more applications are presented in the form of simulation games. From a total of 50 applications for children who play more often downloaded, half of the entire application is presented to convey learning numbers and letters.

Broadly, the one with most quantity is an application that use the concept of edutainment. Then, speculation about the development of children in Indonesia can be seen. If viewed from how the information processed, such as numbers and letters. Then the conventional learning basic science can not be assumed to provide maximum results. Thought the parents of the importance of basic science studies, making this application becomes one of the needed media. The use of advanced gadget and edutainment applications as a replacement media learning outside of school, seen as an opportunity. This become a chance to learn CCI. Particularly, children have been introduced to the computer environment through the application of edutainment games. So that children can adapt to advanced gadgets faster than they should.
Seeing almost the number between edutainment applications and simulation games nearly equal, it would seem the trend in Indonesian children have been taught how to make decisions early on. Creativity, interests and talents can help children to explore and imagine by using the knowledge they just get. This should have the same goal with the approach to model the children mindset. CCI in Indonesia has entered into a process in which how to create designs provide convenience to the child to solve problems and make decisions. Simulation games have been seen as a bridge linking the transition from basic science to the science management. Thus, the evolution of children's development in Indonesia is better than the previous generation.

Although the form of the presentation of each applications different from each other, the second presentation of the applications contained in the data used is almost the same. Especially the design complexity and the interaction that occurs between children of the application used. We found that the offered level of complexity are depending on what they see (What you see is what you get). From many simulation games applications observed, developers find it is difficult to develop a range of knowledge to be conveyed. So to present simulation games and the experience in it, they insert edutainment concept in order to ease the adaptation.

If viewed from the age of the players that play applications, it can be assumed that the application of simulation games will be played after edutainment applications and quality of interaction built when using these advanced gadgets. Industrial applications will consider the type of game players and the number of players who will be used. So first they will consider developing edutainment applications compared to rather than simulation games. So, that the number of applications is dominated by widely played edutainment applications.

\section{CONCLUSION}

From the result showed, it is considered as a new step to see how the process of interaction between children and computers occurs in sophisticated equipment in Indonesia.

From the above analysis, it concludes that the process of Child Computer Interaction can be seen from the number of games applications presented in the form of edutainment and simulation games. Edutainment games and Simulation Games have different forms of interaction, but they have the same goal, namely compressing the knowledge that the developers want to convey, especially in the number of players who use their applications. From many assumptions seen from the number of both applications being played. One form is how part of the application is able to provide new opportunities for studying the CCI for children in Indonesia. By developing one form of the application, mobile application industry opportunities is to prepare interactions that can build the quality of Indonesian children mindset, where this could be done by developing a game edutainment applications and simulation games. Given that the two types of market for game developers increasingly widespread applications. Not mentioned the development of interfaces in the developed application, too. 
CCI's development itself in Indonesia, as seen on the chart showed that edutainment is still more popular than simulation games although simulation games still lost by edutainment. The difference between simulation and edutainment games are not too much different. This indicates children in Indonesia began wanting to play simulation games. And show that CCI in Indonesia keep growing to fit the international market.

\section{REFERENCES}

[1] J.C Read and P. Markopoulos, "Child-Computer Interaction," in:International Journal of Child-Computer Interaction, 2012

[2] J.C. Read and M.M. Bekker, "The Nature of Child Computer Interaction," in: Paper Presented at the HCI 2011, Newcastle, UK, 2011.

[3] Sonia Chiasson and Carl Gutwin , "Design Principles for Children's Technology," 2005.

[4] Amy Bruckman and Alisa Bandlow, "HCI for Kids," Published in: The Human-Computer Interaction Handbook: Fundamentals, Evolving Technologies, and Emerging Applications, 2002.

[5] K.R. Ginsburg, "The importance of play in promoting healthy child development and maintaining strong parent-child bonds," Published in: Pediatrics 119 ,pp 182-191, 2007.

[6] John F. Clark, "History of Mobile Application," Unpublished

[7] A. Druin, Children as Our Technology Design Partners, in The Design of Children's Technology, Allison Druin ed., Morgan Kaufmann, 1999.

[8] Francesco Bellotti et.al, "Assessment in and of Serious Games: An Overview,"2013.

[9] Jiř́ Němec, Josef Trna, "Edutainment or Entertainment.Education Possibilities of Didactic Games in Science Education," in: The Evolution Of Children Play - 24. ICCP Word Play Conference, pp. 5564, 2007.
[10] Tarja Susi, Mikael Johannesson and Per Backlund," Serious Games An Overview", 2007.

[11] Sari Walldén and Anne Soronen, "Edutainment From Television and Computers to Digital Television." Tampere:University of Tampere ,2004.

[12] Hadron Solutions India Pvt. Ltd., "Alphabet Find", http://img.samsungapps.com/product/2013/0410/000000579673/IconIm age_20130410124226086_NEW_WEB_SHOT2_HALF.png,2013.

[13] R. Van Eck, "Digital game based learning: It's not just the digital natives who are restless". EDUCAUSE review, march/april, 2006, pp. 16-30.

[14] P. Hodson, M. Connoly and D. Saunders, "Can computer-bases learning support adult learners?," Journal of Further and Higher Education, 2001, pp. 325-335

[15] Rosemary Garris, Robert Ahlers, James E. Driskell, Games, Motivation, and Learning: A Research and Practice Model. 2002.

[16] R. D. Tennyson and R. L. Jorczak, "A conceptual framework for the empirical study of instructional games," in H. F. O'Neil \& R. S. Perez (Eds.), Computer games and team and individual learning, 2008, pp. 3954). Oxford, UK: Elsevier.

[17] GIGL, "Paradise Island", https://play.google.com/store/apps/ details?id=com.seventeenbullets.android.island\&hl=en,2013

[18] Oleg Alexandrovich Demyanov, "Math and Number of Kids Lite", http://apps.samsung.com/mercury/topApps/topAppsDetail.as?COUNTR Y_CODE=IDN\&productId=000000567698,2013

[19] Quanshuang Qin, "Ice Cream Shop", http://apps.samsung.com/mercury /topApps/topAppsDetail.as?COUNTRY_CODE=IDN\&productId=0000 00586654, 2013.

[20] Distimo Analytics ,http://www.distimo.com/leaderboards/samsungapps/indonesia/kids/free for statistic 23 may 2013. 